\title{
Activation of Presynaptic and Postsynaptic Ryanodine-Sensitive Calcium Stores Is Required for the Induction of Long-Term Depression at GABAergic Synapses in the Neonatal Rat Hippocampus
}

\author{
Olivier Caillard, Yehezkel Ben-Ari, and Jean-Luc Ga"ıarsa \\ Institut de Neurobiologie de la Me' diterrane' e (INMED), Institut National de la Sante' et de la Recherche
}

\author{
Me' dicale U29, B.P. 13, 13273 Marseille Cedex 09, \\ France
}

The role of internal calcium stores in the induction of long-term depression at GABAergic synapses was investigated in the neonatal rat hippocampus. Whole-cell recordings of $\mathrm{CA} 3$ pyramidal neurons were performed on hippocampal slices from neonatal (2-4 d old) rats. In control conditions, tetanic stimulation (TS) evoked an NMDA-dependent long-term depression of $\mathrm{GABA}_{A}$ receptor-mediated postsynaptic responses (LTD GABA-A . LTD GABA-A was prevented when the cells were loaded with ruthenium red, a blocker of $\mathrm{Ca}^{21}$-induced $\mathrm{Ca}^{21}$

In various brain structures, repetitive activation of synaptic connections can lead to a calcium-dependent long-term potentiation (LTP) or long-term depression (LTD) of synaptic transmission, which are held responsible for memory formation or neuronal network development. LTP and LTD are persistent increases or decreases, respectively, in the synaptic strength. In addition to glutamatergic synapses, several recent studies have reported that both LTP and LTD at GABAergic synapses can occur in different brain regions (Kano et al., 1992; Morishita and Sastry, 1993; Komatsu, 1994; Stelzer et al., 1994). Although a postsynaptic rise in intracellular calcium concentration $\left(\left[\mathrm{Ca}^{21}\right]_{\mathrm{i}}\right)$ appears to be the common trigger for inducing synaptic plasticity, the source of calcium and the underlying consequences on synaptic efficacy may differ (Bear and Malenka, 1994; Marty and Llano, 1995; Nicoll and Malenka, 1995). The postsynaptic rise in $\left[\mathrm{Ca}^{21}\right]_{i}$ leading to GABAergic synaptic plasticity can be produced by a calcium entry via NMDA channels (Komatsu and Iwakiri, 1993; Stelzer et al., 1994), by voltage-gated calcium channels (VDCCs) (Kano et al., 1992; Caillard et al., 1999a), or by the release of calcium from InsP3-sensitive internal stores (Komatsu, 1996).

In previous studies (McLean et al., 1996; Caillard et al., 1999b), we have reported that tetanic stimulation of GABAergic and glutamatergic fibers leads to an NMDA-dependent LTD of

$\mathrm{GABA}_{\mathrm{A}}$ receptor-mediated synaptic transmission ( $\mathrm{LTD}_{\mathrm{GABA}-\mathrm{A}}$ ). The induction of LTDGABA-A requires a postsynaptic rise in $\left[\mathrm{Ca}^{21}\right]_{i}$ that is caused, at least in part, by a calcium influx through NMDA channels (Caillard et al., 1999b). The aim of the present study was to investigate the possible contribution of ryanodinesensitive internal calcium stores (Berridge, 1997) in the induction release (CICR) stores, whereas loading the cells with heparin, a blocker of $\mathrm{IP}_{3}$-induced $\mathrm{Ca}^{21}$ release stores, had no effect. The effects of ryanodine, another compound that interferes with CICR stores, were also investigated. Intracellular injection of ryanodine prevented the induction of LTDGABA-A only when the TS was preceded by depolarizing pulses that increase intracellular $\mathrm{Ca}^{21}$ concentration. When applied in the bath, ryanodine prevented the induction of LTDGABA-A. Altogether, these results suggest that ryanodine acts as a $\mathrm{Ca}^{21}$-dependent blocker of CICR stores and that the induction of LTDGABA-A required the activation of both presynaptic and postsynaptic CICR stores.

Key words: synaptic plasticity; development; GABA; glutamate; calcium stores; hippocampus

This work was supported by the Institut National de la Sant'e et de la Recherche M'edicale. Olivier Caillard was supported by a grant from the Ministe`re de l'Enseignement Sup'erieur et de la Recherche.

Correspondence should be addressed to Olivier Caillard, Arbeitsgruppe Zellular Neurobiologie, Max-Plank Institut für Biophysikalische Chemie, Am Fassberg, D-37077 Go“ttingen, Germany. E-mail: ocailla@gwdg.de.

Copyright $\odot 2000$ Society for Neuroscience $\quad$ 0270-6474/00/200001-05 $\$ 15.00 / 0$

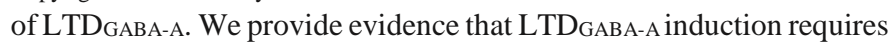
the activation of both presynaptic and postsynaptic ryanodine-sensitive $\mathrm{Ca}^{21}$ stores.

\section{MATERIALS AND METHODS}

Brain slice preparation. Experiments were performed on hippocampal CA3 neurons obtained from postnatal day (P) 2-4 Wistar rats. Brains were removed under cryoanesthesia and submerged in artificial CSF (ACSF) containing (in mM): $\mathrm{NaCl} 126, \mathrm{KCl} 3.5, \mathrm{CaCl}_{2} 2, \mathrm{MgCl}_{2} 1.3, \mathrm{NaH}_{2} \mathrm{PO}_{4} 1.2, \mathrm{NaHCO}_{3} 25$, and glucose 11, pH 7.4, when equilibrated with $95 \% \mathrm{O}_{2}$ and $5 \% \mathrm{CO}_{2}$. Hippocampal slices, $600 \mathrm{~mm}$ thick, were cut with a McIlwain tissue chopper and incubated in $\mathrm{ACSF}$ at room temperature for at least $60 \mathrm{~min}$ before use. Individual slices were then transferred to a submerged recording chamber and perfused with ACSF at $2.5-3 \mathrm{ml} / \mathrm{min}$ at $34^{\circ} \mathrm{C}$

Whole-cell recordings. Whole-cell recordings were performed with an Axopatch 200B (Axon Instruments) amplifier. The pipette solution contained (in mM): $\mathrm{K}$-gluconate $100, \mathrm{CaCl}_{2}$ 0.1, EGTA 1.1, HEPES 10, $\mathrm{CsCl} 20, \mathrm{MgATP}$ 2, $\mathrm{MgCl}_{2}$ 5, cAMP 0.2, NaGTP 0.6, QX314 2, $\mathrm{pH}_{\mathrm{i}} 7.25$, osmolarity 275 mOsm. In some experiments, heparin $(2 \mathrm{mg} / \mathrm{ml})$, ryanodine $(10 \mathrm{~mm})$, or ruthenium red $(20 \mathrm{~mm})$ was dissolved in the pipette solution. Capacitance and membrane resistance were determined by an online fitting analysis of the transient currents in response to a $5 \mathrm{mV}$ pulse with Acquis Software (ACQUIS, G. Sadoc, BioLogic). Compensation parameters were set to $50-70 \%$. Cells recorded with unstable membrane resistance or series resistances were discarded. 
This article is published in The Journal of Neuroscience, Rapid Communications Section, which publishes brief, peer-reviewed papers online, not in print. Rapid Communications are posted online approximately one month earlier than they would appear if printed. They are listed in the Table of Contents of the next open issue of JNeurosci. Cite this article as: JNeurosci, 2000, 20:RC94 (1-6). The publication date is the date of posting online at www.jneurosci.org.

http://www.jneurosci.org/cgi/content/full/4476

$A$

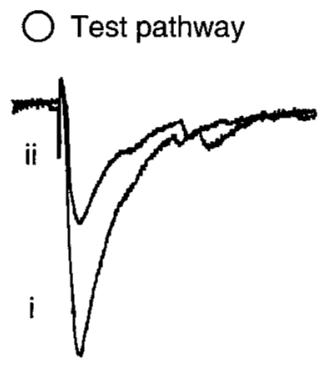

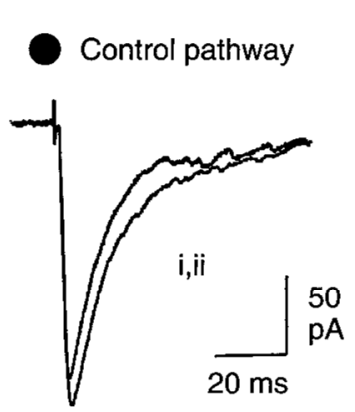

$B$

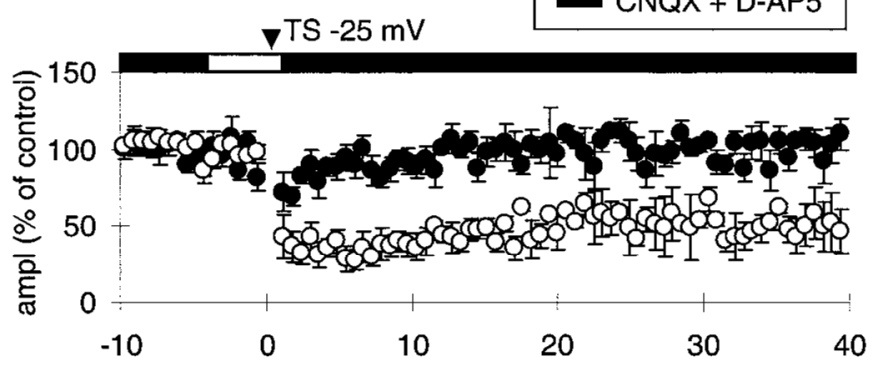

C

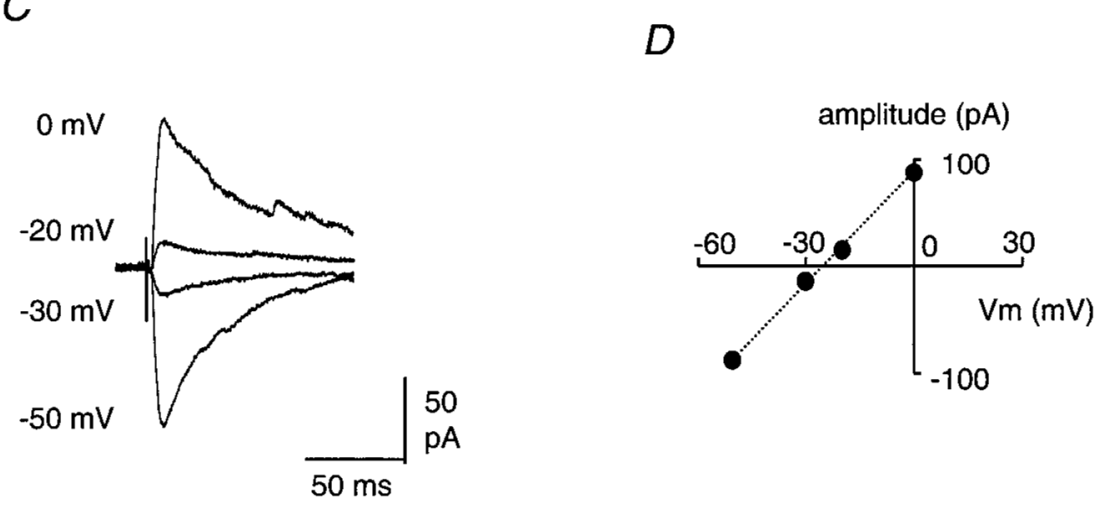

$\left(\mathrm{GABA}_{\mathrm{A}}\right.$ PSCs) at a holding potential of $260 \mathrm{mV}$ (Fig. 1A). After a control period, D-AP5 was washed out, and three TSs $(100 \mathrm{~Hz}, 1 \mathrm{sec}$, three times, $30 \mathrm{sec}$ interval) were delivered to the test pathway in the presence of CNQX (10 mM) alone at a depolarized holding potential ranging from 230 to $225 \mathrm{mV}$ (Fig. 1B). At this potential, which corresponds to the reversal potential of $\mathrm{GABA}_{\mathrm{A}} \mathrm{PSCs}$ with our recording solution (Fig. 1C,D), the voltagedependent blockade of NMDA channels by $\mathrm{Mg}^{21}$ is alleviated (Nowak et al., 1984). This procedure allowed us to measure the NMDA receptor-mediated

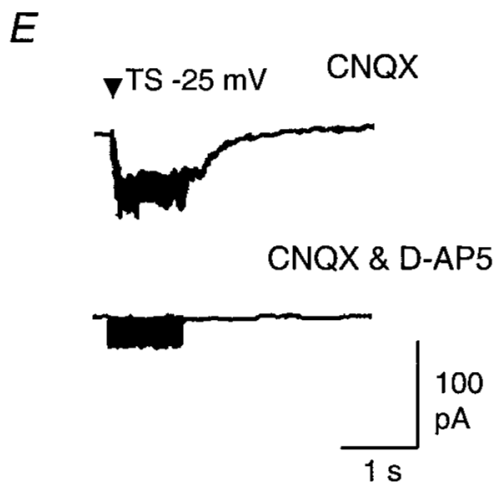

Figure 1. Tetanic stimulation induced $\mathrm{LTD}_{\mathrm{GABA}-\mathrm{A}}$. $A$, Superimposed averaged $\mathrm{GABA}_{\mathrm{A}} \mathrm{PSCs}(n 55)$ of the test and control pathway recorded in CNQX $(10$ mM) and D-AP5 (50 mM) before (i) and $20 \mathrm{~min}$ after (ii) TS. TS was applied to the test pathway at a depolarized holding potential (225 $\mathrm{mV})$ in the presence of CNQX. $B$, Time course of changes in the $\mathrm{GABA}_{\mathrm{A}}$ PSCs amplitude presented as a percentage of pretetanized amplitude on the test (E) and control (F) pathway ( $\left.n 57\right)$. $C$, Superimposed averaged $\mathrm{GABA}_{\mathrm{A}}$ PSCs $(n 55)$ recorded in CNQX (10 mM) and D-AP5 (50 mM) at different holding membrane potentials. $D, I-V$ curve of the averaged $\mathrm{GABA}_{\mathrm{A}}$ PSCs shown in $A$. The reversal potential for $\mathrm{GABA}_{\mathrm{A}}$ PSCs is $225 \mathrm{mV}$. $E$, TS-induced inward currents in CNQX and CNQX 1D-AP5 recorded at the reversal potential of $\mathrm{GABA}_{\mathrm{A}}$ PSCs.

Electrical stimulation $(30-60 \mathrm{msec}, 10-30 \mathrm{~V}, 0.03 \mathrm{~Hz}$ ) of a test and a control pathway was performed with two bipolar tungsten electrodes located in the stratum radiatum on both sides of the recording electrode. Three tetanic stimuli $(100 \mathrm{~Hz}, 1 \mathrm{sec}, 30 \mathrm{sec}$ intervals) were delivered to the test pathway. Tetanic stimulation (TS) was applied between 10 and $12 \mathrm{~min}$ after the seal was broken. The intensity of test and tetanic stimuli was two to three times the threshold required to elicit $\mathrm{GABA}_{\mathrm{A}}$-mediated responses.

Data acquisition, analysis, and drugs. Evoked $\mathrm{GABA}_{\mathrm{A}}$ receptormediated synaptic responses were stored on a personal computer for subsequent analysis (ACQUIS, G. Sadoc, Bio-Logic). To rule out possible rundown of GABAergic responses, the amplitude of the test $\mathrm{GABA}_{\mathrm{A}}$-mediated responses was compared with the control pathway. For data presented as the mean 6 SEM, statistical analysis was performed using a Student's paired $t$ test. Statistical analysis of percentage values was performed with ANOVA tests. Data were judged to differ when $p, 0.05$. 6-Cyano-7-nitroquinoxaline-2,3-dione (CNQX), D(2)2amino-5-phosphovaleric acid (D-AP5), and QX314 were purchased from Tocris Cookson. Heparin, ryanodine, and ruthenium red were purchased from LC Laboratories.

\section{RESULTS}

The protocol used to test the effect of tetanic stimulation on GABAergic synaptic efficacy was the following (Fig. 1). Two independent afferent pathways (control and test) were stimulated alternately to evoke $\mathrm{GABA}_{\mathrm{A}}$ receptor-mediated postsynaptic currents

current induced by TS (Fig. 1E). As already reported in our previous study (Caillard et al., 1999b), TS produced an NMDA receptormediated inward current of $24369 \mathrm{pA}$ and induced a robust homosynaptic LTDGABA-A (Fig. $1 A, B$ ): the average amplitude of the test $\mathrm{GABA}_{\mathrm{A}}$ PSCs was $49611 \%$ of the control pathway 40 min after TS $(p, 0.01, n 510)$.

\section{LTDGABA-A induction requires the activation of postsynaptic $\mathrm{Ca}^{21}$ induced-Ca ${ }^{21}$ release stores}

To investigate the possible contribution of internal calcium stores to

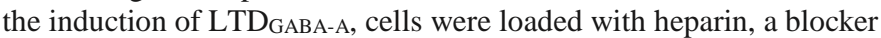
of $\mathrm{InsP}_{3}$ induced-Ca ${ }^{21}$ release (IICR) stores (Berridge, 1993), or ruthenium red, a blocker of $\mathrm{Ca}^{21}$ induced-Ca ${ }^{21}$ release (CICR) stores (Nagasaki and Fleischer, 1989). In cells loaded with heparin $(2 \mathrm{mg} / \mathrm{ml})$, TS applied at $23061 \mathrm{mV}$ produced an average inward current of 260 $65 \mathrm{pA}$ ( $n 57, p 50.14$ when compared with control) and generated a homosynaptic

$\mathrm{LTD}_{\mathrm{GABA}-\mathrm{A}}$ (Fig. $2 A, B$ ): the average amplitude of test $\mathrm{GABA}_{\mathrm{A}}$ PSCs was $4766 \%$ of the control pathway $40 \mathrm{~min}$ after TS $(p, 0.01, n 57)$. In cells loaded with ruthenium red $(20 \mathrm{~mm})$, TS applied at $22962 \mathrm{mV}$ 
induced an average inward current of $24966 \mathrm{pA}$ ( $n 56, p 50.60$ when compared with control) but failed to induce a homosynaptic LTDGABAA (Fig. $2 C, D$ ): the average amplitude of test $\mathrm{GABA}_{\mathrm{A}}$ PSCs was 936 $5 \%$ of the control pathway 40 min after TS ( $p 50.20, n 56$ ). These results therefore suggest that the activation of postsynaptic CICR stores but not postsynaptic IICR is required for the induction of LTDGABA-A.

Caillard et al. • Plasticity of Developing GABAergic Synapses
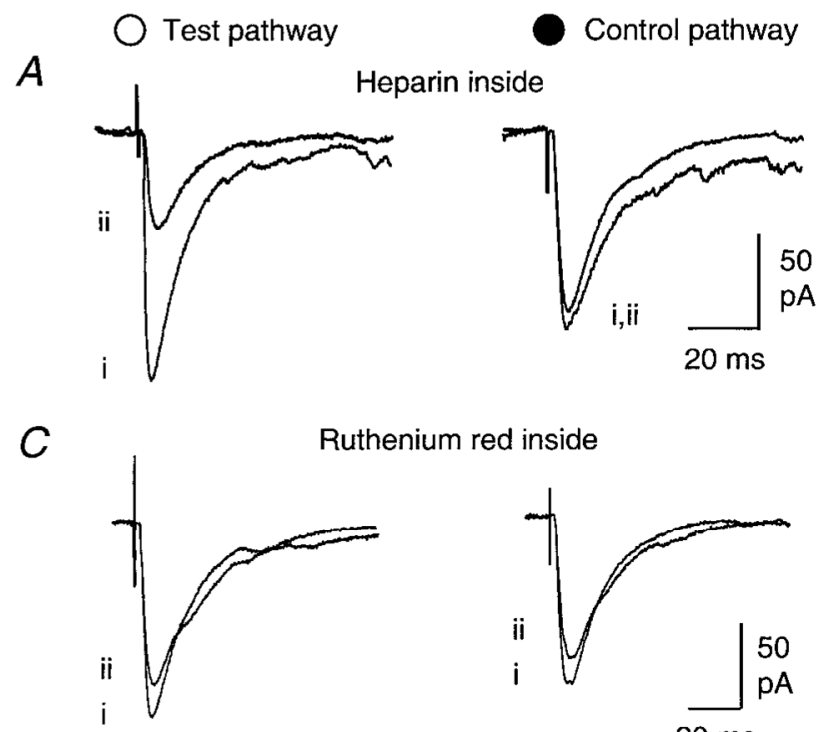

Ruthenium red inside

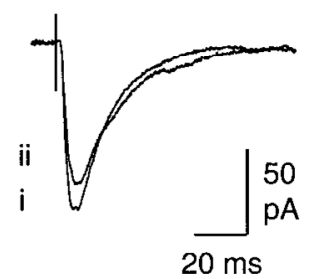

LTDGaba-A. Thus, in control cells TS induced a membrane depolarization of

$2163 \mathrm{mV}$ and a homosynaptic LTD ${ }_{\mathrm{GABA}-\mathrm{A}}$ (Fig. 3C,D): the average amplitude of test GABAA PSPs was $4865 \%$ of the control pathway 40 min after TS ( $p, 0.01, n 57)$. In ryanodineloaded cells, although the amplitude of the TS-induced membrane depolarization was similar to

J. Neurosci., 2000, Vol. 20

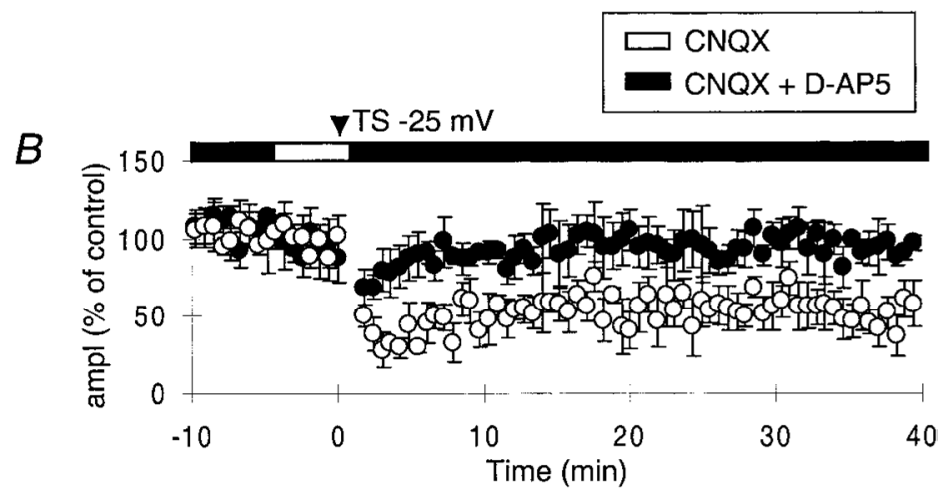

$D$

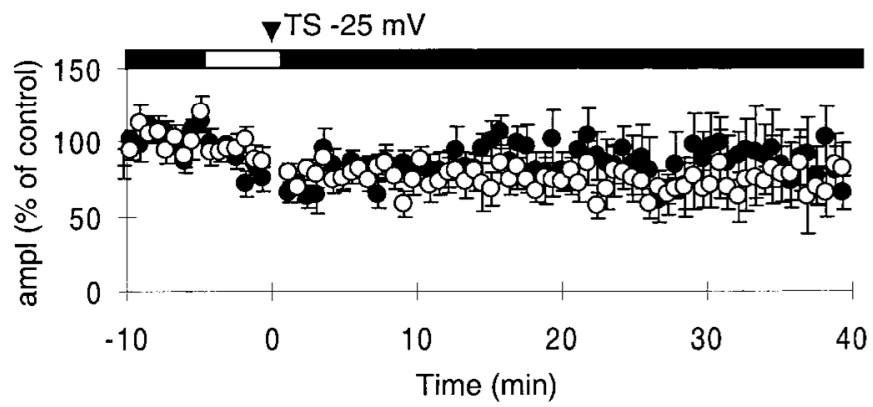

Figure 2. Release of calcium from postsynaptic CICR is required for the induction of LTD $_{\mathrm{GABA}-\mathrm{A}}$. A, Superimposed averaged GABA $\mathrm{A}_{\mathrm{A}} \mathrm{PSCs}(n 55)$ of the test and control pathway recorded in CNQX (10 mM) and D-AP5 (50 mM) before (i) and $20 \mathrm{~min}$ after (ii) TS. TS was applied to the test pathway at a depolarized holding potential $(225 \mathrm{mV})$ in the presence of CNQX. $B$, Time course of changes in the $\mathrm{GABA}_{\mathrm{A}}$ PSCs amplitude presented as a percentage of pretetanized amplitude on the test (E) and control (F) pathway (n 5 7). In $A$ and $B$, the pipette solution contained heparin $(2 \mathrm{mg} / \mathrm{ml})$. $C, D$, Same as in $A$ and $B$ except that the pipette solution contained ruthenium red $(20 \mathrm{mM})$

\section{LTDGaBA-A induction requires the activation of postsynaptic ryanodine-sensitive calcium stores}

To further demonstrate the involvement of postsynaptic CICR in the induction of $\mathrm{LTD}_{\mathrm{GABA}-\mathrm{A}}$, cells were loaded with ryanodine $(10 \mathrm{~mm})$ to block CICR (Nagasaki and Fleischer, 1988; Berridge and Dupont, 1994). Because previous studies have suggested that ryanodine required a rise in $\left[\mathrm{Ca}^{21}\right]_{\mathrm{i}}$ to efficiently interfere with CICR (Kano et al., 1995), the following protocols were designed. In a first set of experiments, ryanodine-loaded cells were recorded in voltage-clamp mode. In a second set of experiments, cells were recorded in currentclamp mode, and 10 depolarizing current pulses $(50 \mathrm{msec}$ duration, $0.03 \mathrm{~Hz}$, one to three action potentials per pulses) (Fig. 3C-E, inset) were applied during the control period to activate the VDCCs. We hypothesized that clamping the cells at a hyperpolarized potential will prevent postsynaptic calcium influx, thus preventing the effect of ryanodine, whereas under current-clamp mode, the activation of VDCCs will allow ryanodine to efficiently act on postsynaptic CICR.

In ryanodine-loaded cells recorded in voltage-clamp mode $\left(V_{\mathrm{h}} 5260\right.$ $\mathrm{mV})$, TS produced an inward current of $24567 \mathrm{pA}$ at $22561 \mathrm{mV}(n$ $57, p 50.84$ when compared with control) and generated a homosynaptic LTDGABA-A (Fig. $3 A, B$ ): the average amplitude of test GABA $_{\mathrm{A}}$ PSCs was $5566 \%$ of the control pathway 40 min after TS ( $p$ , 0.01, $n 57$ ). In current-clamp experiments, however, when VDCCs were activated during the control period to allow postsynaptic $\mathrm{Ca}^{21}$ influx, postsynaptic infusion of ryanodine prevented the induction of control (20 $63 \mathrm{mV}, p 5$ 0.74), TS failed to induce an LTDGABA-A (Fig. $3 E, F)$ : the average amplitude of test $\mathrm{GABA}_{\mathrm{A}}$ PSPs was $10665 \%$ of the control pathway $40 \mathrm{~min}$ after TS ( $p 50.23, n 56$ ). The latter experiment was also performed in voltage-clamp mode ( $n 52$ ). Under these conditions, the application of depolarizing voltage steps to ryanodine-loaded cells also prevented the induction of

LTD GABA-A (data not shown).

These results therefore suggested that ryanodine acts as a $\mathrm{Ca}^{21}$ dependent blocker of CICR stores and confirmed that postsynaptic ryanodine-sensitive calcium stores are involved in the induction of LTDGABA-A.

\section{LTD presynaptic ryanodine-sensitive calcium stores}

Having established that ryanodine required a postsynaptic rise in $\left[\mathrm{Ca}^{21}\right]$ i to act on CICR, we thought to test the effect of bathapplied ryanodine to investigate the contribution of presynaptic CICR. We reasoned that under voltage-clamp recording, bathapplied ryanodine, which permeates both presynaptic and postsynaptic membranes, will only act at presynaptic levels because spontaneous and evoked activities triggered by presynaptic calcium rises are present. When ryanodine $(10 \mathrm{~mm})$ was applied by bath during the washout of D-AP5, it prevented the induction of $\operatorname{LTD}_{\mathrm{GABA}-\mathrm{A}}$ (Fig. $4 A, B$ ): the average amplitude of test $\mathrm{GABA}_{\mathrm{A}}$ PSCs was $10868 \%$ of the control pathway 
4 of 5 J. Neurosci., 2000, Vol. 20

40 min after TS ( $p 50.22, n 55$ ). In this condition, the amplitude of the inward current induced by TS was similar to that evoked in control conditions (248 $66 \mathrm{pA}$ at $22661 \mathrm{mV}, n 57, p 50.77$ when compared with control).

Altogether, the observation that ryanodine prevented LTD ${ }_{\mathrm{GABA}} \mathrm{A}$ when applied in the bath but not when loaded into the recorded cell unless a postsynaptic rise in $\left[\mathrm{Ca}^{21}\right]_{\mathrm{i}}$ was induced suggested that presynaptic CICR stores were required for the induction of LTDGABAA.

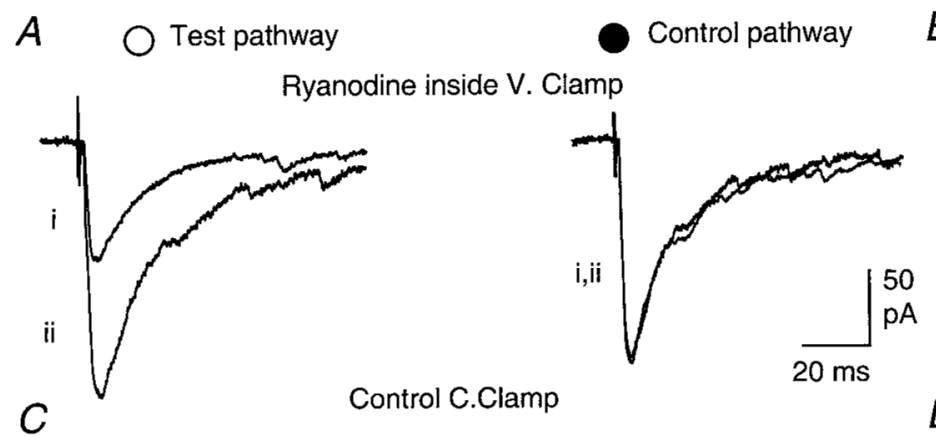

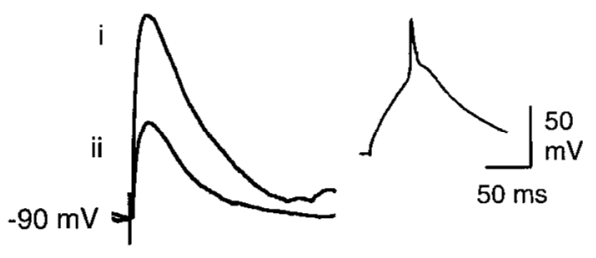

E

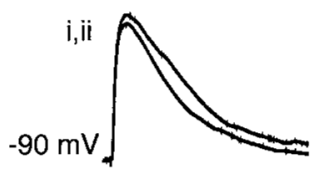

Ryanodine inside C.Clamp

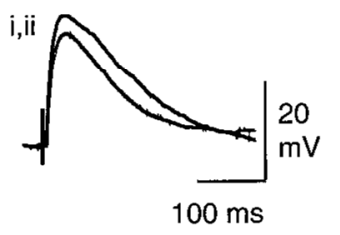
loaded cells, the amplitude of the inward current or membrane depolarization generated by TS did not differ from that induced in control conditions, thus ruling out unspecific effects on postsynaptic NMDA receptors, which must be activated for the induction of LTDGabA-A (Caillard et al., 1999b). Several studies have reported that although spatially distinct, IICR and CICR stores can interact mutually. For instance, ryanodine was shown to empty IP3-sensitive pools in CA1 pyramidal neurons (Nakamura et al., 1999) and cerebellar Purkinje cells (Khodakhah and Armstrong, 1997). As such,

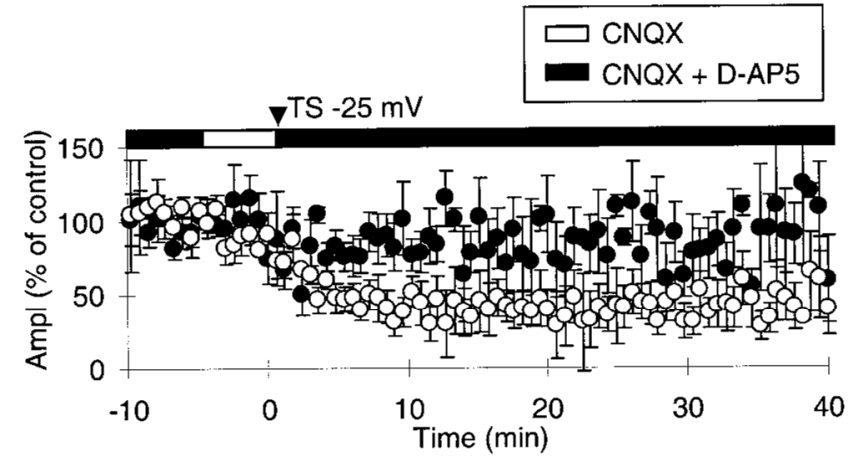

$D$
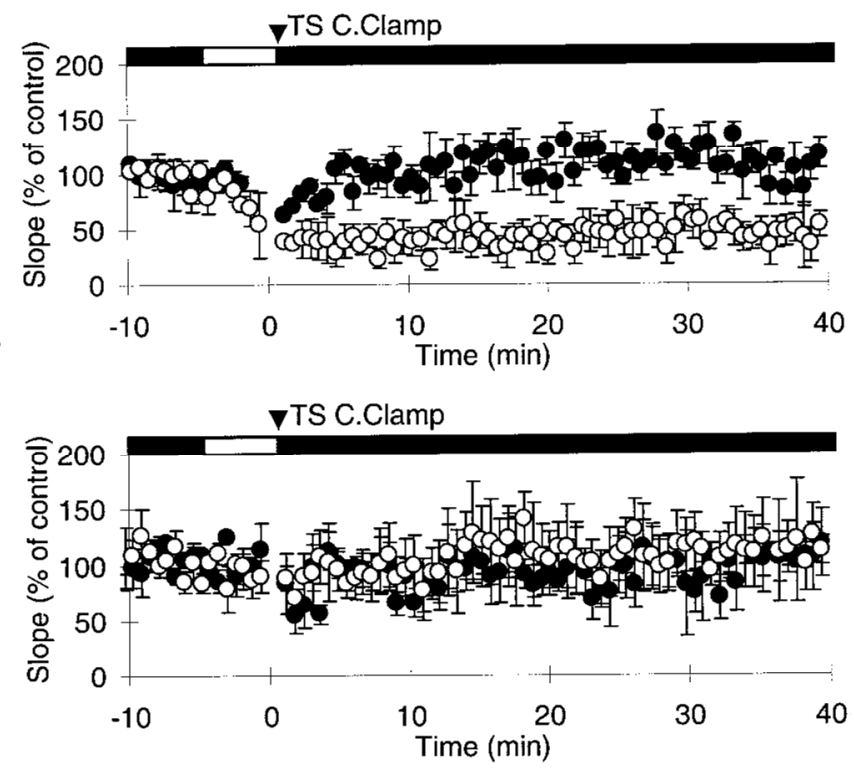

Figure 3. Ryanodine requires a rise in $\left[\mathrm{Ca}^{21}\right]_{\mathrm{i}}$ to act on CICR. A, Superimposed averaged $\mathrm{GABA}_{\mathrm{A}}$ PSCs $(n 55)$ of the test and control pathway recorded in CNQX $(10 \mathrm{~mm})$ and D-AP5 $(50 \mathrm{mM})$ before $(i)$ and $20 \mathrm{~min}$ after (ii) TS in ryanodine-loaded cells. TS was applied to the test pathway at a depolarized holding potential (225 $\mathrm{mV}$ ) in the presence of CNQX. B, Time course of changes in the GABA $\mathrm{ASCs}_{\mathrm{A}}$ amplitude presented as a percentage of pretetanized amplitude on the test (E) and control (F) pathway ( $n$ 5 7). $C$, Superimposed averaged GABA $\mathrm{A}_{\mathrm{A} P \mathrm{~s}}(n 55)$ of the test and control pathway recorded in CNQX (10 mM) and D-AP5 (50 mM) before (i) and 20 min after (ii) TS. TS was applied to the test pathway at a depolarized membrane potential $(225 \mathrm{mV})$ in the presence of CNQX. The middle trace shows the response to a depolarizing current step $(50 \mathrm{msec}, 250 \mathrm{pA})$ given during the control period $(0.03 \mathrm{~Hz})$. $D$, Time course of changes in the GABA $\mathrm{A}_{\mathrm{A}}$ PSs amplitude presented as a percentage of pretetanized amplitude on the test (E) and control (F) pathway ( $n 57) . E, F$, Same as in $A$ and $B$ except that the cells were loaded with ryanodine $(10 \mathrm{mM})$.

\section{DISCUSSION}

The results presented here provide evidences that $\mathrm{LTD}_{\mathrm{GABA}-\mathrm{A}}$ induction requires the activation of both presynaptic and postsynaptic ryanodinesensitive calcium stores.

\section{LTD $D_{\text {GABA-A }}$ induction requires the activation of postsynaptic CICR}

Our conclusion that postsynaptic stores are involved in the induction of LTD GABA-A $_{\text {is }}$ supported by the fact that loading the recorded neurons with ruthenium red or ryanodine (provided that a postsynaptic calcium rise occurred; see below) (Berridge and Dupont, 1994) prevents the induction of $\mathrm{LTD}_{\mathrm{GABA}} \mathrm{A}$. In ruthenium red- or ryanodine- the preventive effect of ryanodine may be accounted for by the interaction with IICR. This hypothesis appears extremely unlikely, however, because ruthenium red, a blocker of CICR that does not interact with IICR, also prevented the induction of

LTDGABA-A.

In a previous study we reported that the induction of LTD ${ }_{\mathrm{GABA}-\mathrm{A}}$ requires a postsynaptic increase in $\left[\mathrm{Ca}^{21}\right]_{\mathrm{i}}$, provided by an influx of calcium through NMDA channels (Caillard et al., 1999b). The present results suggest that this signal has to be magnified by calcium release from CICR to induce LTD $_{\mathrm{GABA}-\mathrm{A}}$. A postsynaptic amplification of an NMDA channel-mediated rise in $\left[\mathrm{Ca}^{21}\right]_{i}$ that may play an inductive role in LTD of glutamatergic synaptic transmission (Reyes and Stanton, 1996) has been reported in the adult hippocampus 
(Segal and Manor, 1992; Alford et al., 1993; Emptage et al., 1999). In the visual cortex, LTP of GABAergic synaptic transmission involves the activation of IICR stores (Komatsu, 1996). There are also suggestions that IICR stores may be involved in the induction of glutamatergic LTD in the cerebellum (Daniel et al., 1998) and CA1 hippocampal region (Reyes and Stanton, 1996). In the present study, we have shown that loading the cells with heparin does not prevent the

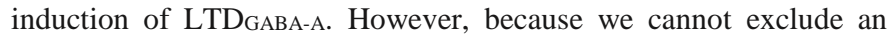
inefficient dialysis of the recorded cell, the possible

$$
\text { A }
$$
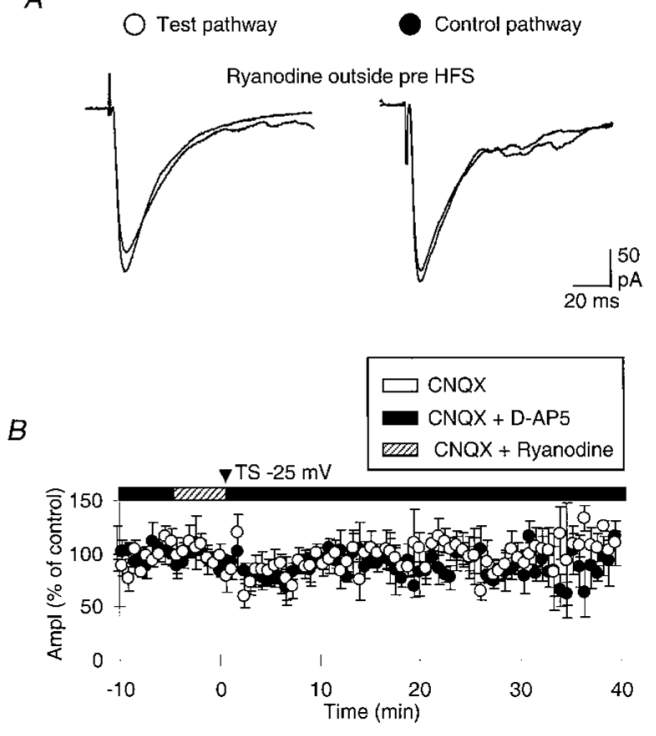

Caillard et al. • Plasticity of Developing GABAergic Synapses

Figure 4. Activation of presynaptic ryanodine-sensitive calcium stores is required for the induction of LTD $_{\mathrm{GABA}-\mathrm{A}}$. $A$, Superimposed averaged $\mathrm{GABA}_{\mathrm{A}}$ PSCs $(n 55)$ of the test and control pathway recorded in CNQX $(10 \mathrm{mM})$ and D-AP5 (50 mM) before (i) and $20 \mathrm{~min}$ after (ii) TS. TS was applied to the test pathway at a depolarized holding potential $(225 \mathrm{mV})$ in the presence of CNQX and ryanodine $(10 \mathrm{~mm}) . B$, Time course of changes in the $\mathrm{GABA}_{\mathrm{A}} \mathrm{PSCs}$ amplitude presented as a percentage of pretetanized amplitude on the test (E) and control (F) pathway (n 5 7).

contribution of the IICR stores remains questioned. Although we cannot completely exclude the involvement of IICR stores, our results show that the activation of postsynaptic CICR is necessary to reach the postsynaptic $\left[\mathrm{Ca}^{21}\right]_{\mathrm{i}}$ threshold required to trigger LTD $\mathrm{GABA}_{\mathrm{A} A}$.

\section{LTD $D_{\text {GABA-A }}$ induction requires the activation of presynaptic CICR}

There are some suggestions regarding the involvement of presynaptic CICR stores in the induction of synaptic plasticity. Thus, calciumsequestering ability associated with the endoplasmic reticulum is present on presynaptic nerve terminals (Hartter et al., 1987; Finch et al., 1991; Sharp et al., 1993), and a possible contribution of presynaptic stores in the induction of LTD at glutamatergic hippocampal synapses has been reported (Reyes and Stanton, 1996). The suggestion that the activation of presynaptic ryanodine-sensitive calcium stores is also required for the induction of LTD GABA-A $_{\text {is }}$ based on the observation that bath application of ryanodine, which permeates both presynaptic and postsynaptic membranes, did block the induction of LTD GABA-A, $_{\text {, }}$ whereas a postsynaptic infusion did not unless postsynaptic rises in calcium were induced before TS. The latter is likely attributable to a calcium-dependent action of ryanodine on CICR (Kano et al., 1995) and not to an inefficient dialysis of the recorded cells, because in all experiments (with or without postsynaptic rises in calcium) TS was delivered within 10 to $12 \mathrm{~min}$ after breaking the seal. Furthermore, ryanodine did not alter the TS-induced postsynaptic responses, showing that NMDA-mediated responses were not affected.

We interpret our results, taken all together, as follows. In voltageclamp experiments, the postsynaptic cell is held at a hyperpolarized potential. In this condition, no postsynaptic rise in calcium occurred, thus preventing the effects of ryanodine on CICR either applied to the bath or into the recorded cell. However, at the presynaptic level, calcium rise do occur, as revealed by the presence of both spontaneous and evoked activities, and bath-applied ryanodine could efficiently deplete presynaptic CICR, thus preventing the induction of LTDGABAA.

\section{Conclusion}

In summary, we have provided evidence that the induction of LTD $_{\text {GABA-A }}$ required the activation of postsynaptic and presynaptic ryanodine-sensitive calcium stores. Further experiments are required to clarify the mechanisms leading to the activation of presynaptic ryanodine-sensitive calcium stores. In a previous study we have shown that LTD $_{\text {GABA-A }}$ is homosynaptic and likely expressed presynaptically as a decrease in quantal content (Caillard et al., 1999b). The presynaptic ryanodine-sensitive calcium stores could therefore have a permissive role and act in synergy with the actions of a putative retrograde messenger released from the postsynaptic site. This latter hypothesis may explain why $\mathrm{LTD}_{\mathrm{GABA}-\mathrm{A}}$ is expressed only at tetanized fibers.

\section{REFERENCES}

Alford S, Frenguelli BG, Schofield JG, Collingridge GL (1993) Characterization of the $\mathrm{Ca}^{21}$ signals induced in hippocampal CA1 neurones by the synaptic activation of NMDA receptors. J Physiol (Lond) 469:693-716.

J. Neurosci., 2000, Vol. 20

Bear MF, Malenka RC (1994) Synaptic plasticity: LTP and LTD. Curr Opin Neurobiol 4:389-399.

Berridge MJ (1993) Inositol trisphosphate and calcium signalling. Nature $361: 315-325$

Berridge MJ (1997) Elementary and global aspects of calcium signalling. J Physiol (Lond) 499:291-306.

Berridge MJ, Dupont G (1994) Spatial and temporal signalling by calcium. Curr Opin Cell Biol 6:267-274.

Caillard O, Ben Ari Y, Ga iarsa J-L (1999a) Long-term potentiation of GABAergic synaptic transmission in neonatal rat hippocampus. J Physiol (Lond) 518:109-119.

Caillard O, Ben Ari Y, Ga“ 1arsa J-L (1999b) Mechanisms of induction and expression of long-term depression at GABAergic synapses in the neonatal rat hippocampus. J Neurosci 19:7568-7577. Daniel H, Levenes C, Cr'epel F (1998) Cellular mechanisms of cerebellar LTD. Trends Neurosci 21:401-407.

Emptage N, Bliss TV, Fine A (1999) Single synaptic events evoke NMDA receptor-mediated release of calcium from internal stores in hippocampal dendritic spines. Neuron 22:115-124.

Finch EA, Turner TJ, Goldin SM (1991) Calcium as a coagonist of inositol 1,4,5-trisphosphate-induced calcium release. Science 254:443-446.

Hartter DE, Burton PR, Laveri LA (1987) Distribution and calciumsequestering ability of smooth endoplasmic reticulum in olfactory axon terminals of frog brain. Neuroscience 23:371-386.

Kano M, Garaschuk O, Verkhratsky A, Konnerth A (1995) Ryanodine receptormediated intracellular calcium release in rat cerebellar Purkinje neurones. J Physiol (Lond) 487:1-16.

Kano M, Rexhausen U, Dreessen J, Konnerth A (1992) Synaptic excitation produces a long-lasting rebound potentiation of inhibitory synaptic signals in cerebellar Purkinje cells. Nature 356:601-604.

Khodakhah K, Armstrong CM (1997) Inositol trisphosphate and ryanodine receptors share a common functional $\mathrm{Ca}^{21}$ pool in cerebellar Purkinje neurons. Biophys J 73:3349-3357.

Komatsu Y (1994) Age-dependent long-term potentiation of inhibitory synaptic transmission in rat visual cortex. J Neurosci 14:6488-6499.

Komatsupostsynaptic inositol trisphosphate-induced CaY (1996) $\mathrm{GABA}_{B}$ receptors, monoamine 21 release are involvedreceptors, and in the induction of long-term potentiation at visual cortical inhibitory synapses. J Neurosci 16:6342-6352.

Komatsu Y, Iwakiri M (1993) Long-term modification of inhibitory synaptic transmission in developing visual cortex. NeuroReport 4:907-910. Marty A, 
6 of $5 \mathrm{~J}$. Neurosci., 2000, Vol. 20

Llano I (1995) Modulaton of inhibitory synapses in the mammalian brain. Curr Opin Neurobiol 5:335-341.

McLean HA, Caillard O, Ben-Ari Y, Ga iarsa J-L (1996) Bidirectional plasticity expressed by GABAergic synapses in the neonatal rat hippocampus. J Physiol (Lond) 496:471-477.

Morishita W, Sastry BR (1993) Long-term depression of IPSPs in rat deep cerebellar nuclei. NeuroReport 4:719-722.

Nagasaki K, Fleischer S (1988) Ryanodine sensitivity of the calcium release channel of sarcoplasmic reticulum. Cell Calcium 9:1-7.

Nagasaki K, Fleischer S (1989) Modulation of the calcium release channel of sarcoplasmic reticulum by adriamycin and other drugs. Cell Calcium 10:6370.

Nakamura T, Barbara JG, Nakamura K, Ross WN (1999) Synergistic release of $\mathrm{Ca}^{21}$ from IP3-sensitive stores evoked by synaptic activation of mGluRs paired with backpropagating action potentials. Neuron 24:727-737.

Nicoll RA, Malenka RC (1995) Contrasting properties of two forms of longterm potentiation in the hippocampus. Nature 377:115-118.

Nowak L, Bregestovski P, Ascher P, Herbet A, Prochiantz A (1984) Magnesium gates glutamate-activated channels in mouse central neurones. Nature 307:462-465.

Reyes M, Stanton PK (1996) Induction of hippocampal long-term depression requires release of $\mathrm{Ca}^{21}$ from separate presynaptic and postsynaptic intracellular stoves. J Neurosci 16:5951-5960.

Segal M, Manor D (1992) Confocal microscopic imaging of $\left[\mathrm{Ca}^{21}\right]_{\mathrm{i}}$ in cultured rat hippocampal neurons following exposure to $N$-methyl-Daspartate. J Physiol (Lond) 448:655-676.

Sharp AH, McPherson PS, Dawson TM, Aoki C, Campbell KP, Snyder SH (1993) Differential immunohistochemical localization of inositol 1,4,5trisphosphate- and ryanodine-sensitive $\mathrm{Ca}^{21}$ release channels in rat brain. $\mathrm{J}$ Neurosci 13:3051-3063.

Stelzer A, Simon G, Kovacs G, Rai R (1994) Synaptic disinhibition during maintenance of long-term potentiation in the CA1 hippocampal subfield. Proc Natl Acad Sci USA 91:3058-3062. 